\title{
NHS 1948-88: less ideology, more humanity
}

\section{An extra $£ 500$ m annually would buy time to think}

British anniversaries, Aldous Huxley said, tend to be more funerals than fetes, ' but this is no reason to ignore the 40th anniversary of the National Health Service. For one thing, some of the pioneers are still around to tell the tale ( $p 000)$; for another, the NHS has become the prime topic for political debate. Hardly a week passes without some new plan for the service, while a secret cabinet committee is undertaking an internal review.' As Britain was the first major western country to have unrestricted entitlement to health care funded by taxation the time may be ripe to ask whether some other pattern would serve us better. ${ }^{3}$ Is the NHS underfunded? Might appreciable savings be made by further cash limits and privatisation of services? And would an increased contribution from the private sector benefit the state scheme?

The reasons for the increased demands on all health services are well known. Western populations are getting older, and many medical advances are expensive. Capital costs are often high-for instance, with nuclear magnetic reasonance machines or lithotripters-but revenue costs may be even higher, particularly if the technology is extended to all those who might benefit. Patients' expectations have also risen, and childless couples want their infertility relieved as a right ( $p 80$ ). Finally, three quarters of the costs of the NHS are on staff, many of whom can command high salaries outside. The service must thus either pay better salaries-as it has done with doctors and nurses-or try to get away with paying less than the going rate. Such parsimony may create severe difficulties in, for example, laboratory and pharmacy services and result in expensive locum and agency fees.

Despite the government recognising these increased demands-and health ministers agreeing targets to meet them-its expenditure has failed to keep up. The target was a $2 \%$ annual increase (1\% a year for the elderly, $0.5 \%$ for medical advances, and $0.5 \%$ for policy objectives, such as better social care) ${ }^{+}$but the reality was $1 \cdot 4 \% .{ }^{5}$ In particular, until this year under its cash limits programme the government had refused to fund the excess cost of hospital pay awards over its own provision for general inflation.

\section{Success story}

The effects of this underfunding have been concentrated on the acute services, particularly the cash limited hospital services. Before considering these, however, it is worth emphasising that the success story of the British NHS has been the sector not subject to cash limits-the family practitioner service. Although the service has its problems, particularly in the inner cities, it manages $90 \%$ of all episodes of ill health for less than $8 \%$ of total NHS spending (with over $70 \%$ of consultations taking place within a day of the patient seeking help). 5 Furthermore, its "gatekeeper" role in preventing unlimited access to specialists ensures that our hospital admission rates are among the lowest in the world. ${ }^{5}$ In the 40 years of the NHS the organisation of general practice has changed with the appearance of group practices, purpose designed centres, and ancillary teams. Vocational training has also developed. As a result of all this-and the creation of an academic base in the Royal College of General Practitionersmedical students now see general practice as a good choice, and over three quarters of patients are happy with the service.

In contrast in 1986 only $67 \%$ of inpatients and $55 \%$ of outpatients were very or quite satisfied with the NHS. ${ }^{5}$ The reasons for this lie both in the distant and in the recent past. The wartime Emergency Medical Service and the NHS took over a stock of ramshackle and outdated voluntary and local authority hospitals. In particular, for some years before the war many of the voluntary agencies had been unable to cope without a subsidy from public funds. Thus, says Webster, the official NHS historian, state intervention was not "a gratuitous extension of state power. It was rather an unavoidable necessity, owing to the collapse of charitable effort." 3

Such, however, were the strains on the NHS itself - not to mention the priorities for repairing war damage and building new houses and schools - that little new hospital building was done for ten years. By then Britain was in one of its periodic economic crises and ambitious programmes had to be curtailed. Not surprisingly the consultants interviewed by Tessa Richards remember being more impressed by the new therapeutic advances, such as penicillin, than they were by any organisational changes ( $\mathrm{p} 49$ ).

Lamentably during the prosperous years in the 1960s before the oil crisis in the early 1970s Britain (unlike other countries) failed to complete a massive programme of new building and refurbishment. ${ }^{6}$ Certainly many new hospitals were built, but many were not completed and penny pinching was the rule. This contrasted with an important success of the service: a nationwide spread of well trained consultants who steadily raised the standards of clinical care despite restraints on services. The failures in building resulted in inefficiency, in that two phases of a new hospital might be in one part of a town, but the linked ancillary departments remained in the old building some distance away. Another consequence of economies was that standards, particularly of finish, were too low for the amount of maintenance they received. 
So it came as no surprise that the National Audit Office has recently found a $£ 2000 \mathrm{~m}$ backlog of maintenance on NHS hospitals. The results of this and the loss of 3500 beds in 1987 have been documented by Tony Smith earlier this year in "Conversations with Consultants": a national waiting list of 682000 in 1986, a perpetual shortage of beds, demoralised staff in short supply, and filthy wards and public areas. ${ }^{8}$ Others have reported similar findings (see box).

Despite the redistribution of funds under RAWP (resource allocation working party) such problems are not confined to the losing areas. In Cornwall (a RAWP gaining area), for example, Thould has described similar difficulties with funding and bed closures as well as transport problems for poor patients in rural areas."

The other influences on costs have received much lip service but generated too little action. Firstly, preventive medicine is approved by all but its potential for long term saving has been ignored in the face of the pressing priorities of acute medicine. Secondly, successive governments have advocated shifting the care of chronic patients from institutions into the community, a policy judged to be socially compassionate. It also happens to free expensive hospital beds, but the policy has taken insufficient account of the social and financial burden on the community, including, of course, the primary care services. Indeed, the policy exposes a historical and expensive administrative anachronism in the NHS: the gap between primary care and the hospital service.

To try to contain expenditure on the NHS, since 1981-2 attention has been concentrated on efficiency savings and cost improvements, primarily in the hospital service, which absorbed $65 \%$ of the NHS's $£ 20.7$ billion budget in 1987 . Obviously in a service as monolithic as the NHS there was scope for such exercises, and the forecast cumulative sum for this year is $£ 577$ million ( $4 \cdot 8 \%$ of the budget). ${ }^{5}$ But half of these savings have arisen from "rationalisation" of patient services and privatisation, and the price has been heavy in terms of bed shortages and squalor. ${ }^{12}$ Most observers would now find it difficult to see where further important savings can be made in the acute services.

Hence the emphasis has now swung to suggestions for fine tuning within the service, such as internal markets (competitive tendering between health authorities for services), and, more radically, to different methods of funding.

There are still only three alternative options for financing health care: user charges, an earmarked tax for the NHS, and private insurance. ${ }^{13}$ All are irrelevant, Klein suggests, if the government does not have the will to spend more on the service. Conversely, while admitting the advantages of the present system as a cheap means of collecting contributions, Maxwell argues that there is a case for insurance fundingwhich allows an intelligent public discussion among the public, employer, and insurer about what benefits can be funded and what cannot. ${ }^{1+}$ Nevertheless, he concludes, simply to increase private spending outside the NHS is unlikely to solve the problem, and it would hasten the development of a two tier system of health care.

Increased private spending on health care (with or without tax incentives) has bulked large in recent government thinking, given that it might be one way of bridging the gap between what Britain spends on health care and what other countries do. Some $7 \%$ of the total beds in our acute sector are private, though their geographical distribution is uneven and the procedures carried out in them are limited. ${ }^{5}$ Though the private sector might have a limited role, for example, in major capital developments (and even in providing cheaper services to the $\mathrm{NHS}^{15}$ ), its expansion from its present 3\% to, say, $20 \%$ would deprive the NHS of one of its basic principles, equity, and threaten standards even more. As a former permanent
"We are not looking for money ourselves at all. We are looking at money for patients. That is our concern." Sir Raymond Hoffenberg, PRCP, to Commons social services committee. ${ }^{\circledR}$

"I cannot justify to you why my local accident and emergency department should be better equipped than ones I have seen in the Third World, but I am surprised that its facilities are worse. . . . How do [people] respond when their first sight of a hospital is of two student nurses and a patient's relative struggling with two trolleys, a closed children's ward on one side, a condemned lift on the other, and between them and the $x$ ray department an obstacle course of buckets and basins carefully positioned under a leaking roof." (King's College Hospital, a major health service for South East London, where the choice had to be made between renovating the accident and emergency department-planned in 1910 for a third of the number of patients - or building a new theatre block.)

"Finally [Lewisham's unit director of policy and planning] admitted 'All right, it needs rewiring, it needs re-painting, it needs re-flooring, it needs repairing, it needs upgrading. But last year we had an overspend of $£ 950000$. We hope to reduce that this year."' (Lewisham Hospital, where, despite a rising birth rate, maternity beds have been cut from 60 to $49 .{ }^{10}$ )

"One gets the impression that people do not believe what is going on." Mr Ian Todd, PRCs, to Commons social services committee.

secretary to the Department of Health and Social Security has emphasised, what is needed is a constructive partnershipbut the private sector must not rob the NHS of essential nursing staff or detract from the responsibilities of NHS consultants (the so called "internal brain drain"). ${ }^{16}$

Britain is not alone in all these debates: countries as widely different as Norway, West Germany, France, The Netherlands, and New Zealand are all reviewing their health systems. ${ }^{17}$ Nevertheless, one country with the widest experience of the extremes of private enterprise must be the United States, and a recent review shows what may happen when health care becomes an economic product and its delivery a business.

Polarising the two views of medicine-the economic and the social-Arnold Relman, the editor of the New England Fournal of Medicine, instances the causes of disastrous medical inflation in the United States: expanding technology, medical professionals reimbursed for each item of service, an open ended insurance system, and over two decades of unregulated proliferation of hospitals. ${ }^{18}$ Between 1966 and 1984 the result was a $60 \%$ real growth in personal expenditure on health care; this has now become $11 \%$ of gross national product. Not surprisingly, those paying for most of the costs (the federal government and large businesses) say that they can no longer afford to subsidise the system. Added to this has been the rise of health care businesses (hospitals, walk in centres, and health maintenance organisations), growing at a compound rate of $10-15 \%$ a year, with their potential for conflict of interest for the doctors they employ. Both types of hospital (for profits and non-profit) are competing for patients to fill their half empty beds. Thus non-profit hospitals can no longer afford to treat the indigent, support expensive teaching programmes, or offer standby and community services that are costly and unprofitable. "The most pressing problem in our health care system today is its inequity," Relman concludes, and that Britain has little to learn from the Americans was one conclusion to come out at a recent conference: "You cannot expect a patient with anorexia to 
learn much from one with obesity." Significantly, also, Relman's state of Massachusetts has recently ended the inflationary spiral in costs by passing a law making universal health insurance compulsory (p 9).2"

In Britain a proliferation of sources of money would not only weaken financial control but also be administratively expensive and increase bureaucracy, and a growing private sector would damage fairness."- These changes might further diminish the overwhelming public popularity that the NHS has had until recently. It is also doubtful whether the NHS can stand a further "disorganisation" "- - yet another massive change in its structure-including closer collaboration between hospitals and general practice, which is not to say that efficiencies should not be a priority for all aspects. Certainly there may be incompetence in the NHS just as there is in other walks of life, including defence procurement, the Passport Office, and the Treasury. (It has been claimed that it was a serious lapse within the health departments and the Treasury in producing an unrealistically low estimate for the first year that got the NHS off to such a bad start.") Such incompetence must be identified and put right.

But competence cannot come without the tools for the job. Just as it would be impossible to run the $B M \mathcal{F}$ without first class business management and accurate financial statements, it is surely impossible to run a multibillion pound service without high quality managers and meaningful statistics. Smith's conversations found that the former were often inadequate, and even obstructive (a view confirmed by $\mathrm{Mr}$ Grant Williams; p 53), and 40 years after 1948 doctors are still waiting for accurate measures of output. Only given accurate data-and the Körner reforms and clinical budgeting are aiming to help this-can doctors fulfil their professional responsibility of playing a full part in audit, recognising and explaining why their outputs may differ from others, and taking suitable corrective action. Only then can a useful public debate be held to achieve a consensus on what the NHS should provide and what it should not provide, perhaps on the shrewd suggestions of Sir Bryan Thwaites."

To conclude, then, there is no argument for major administrative manipulations of the NHS or for different methods of funding as a solution to current problems. It is incumbent on those proposing such changes to show before- hand not only that they will work, be more efficient, and preserve equity but also that they will be superior to further money for the acute services. For most commentators have concluded that the current decline has been induced by cash limits and that adding no more than $5 \%$ of the hospital budget (£500m a year) would have avoided all the talk of crisis, "1: yet just last week the government refused again to make any more money available (p 9). (Interestingly, such a move would bring Britain's spending on health care into line with that of its civilised neighbours.) Such an increase would, of course, do nothing for the capital troubles of the acute services (or problems elsewhere, such as deprivation and poor housing, which have a direct bearing on ill health). Yet it would command public support-two thirds of the population would be willing to pay a further $£ 1$ a week tax guaranteed extra for the NHS - and it would help to preserve one of the world's bravest attempts at universal welfare, one with the still untarnished objective: "to ensure that everybody in the country-irrespective of means, age, sex, or occupationshall have equal opportunity to benefit from the best and most up to date medical and allied services available."

Editor, $B M 7$

STEPHEN LOCK

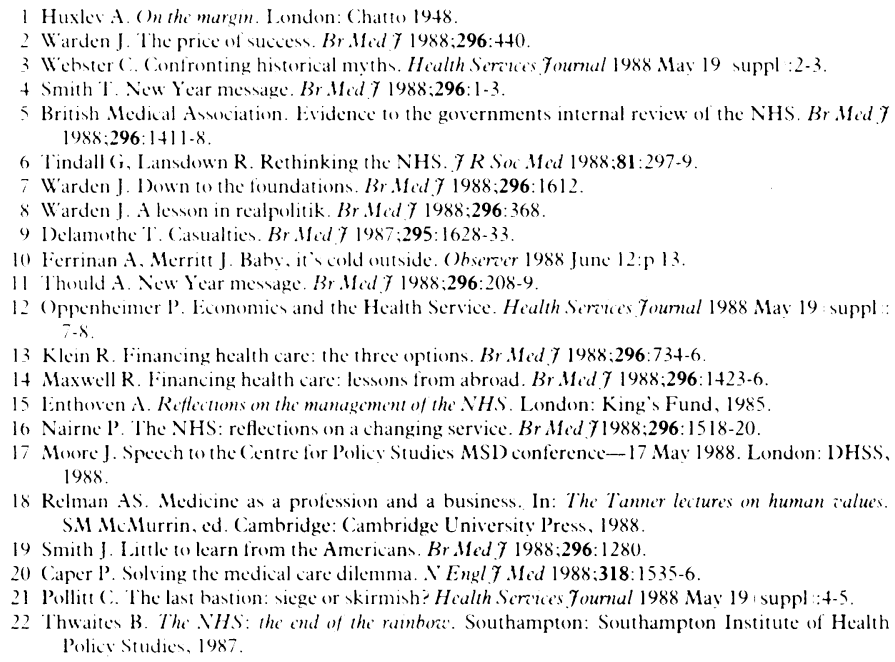

\section{Life sustaining technologies and the elderly}

\section{Americans badly need geriatricians}

Life-sustaining Technologies and the Elderly, a report to the 100th United States Congress by the Office of Technology Assessment, was first requested in 1984 "to provide an array of options for public policy that will support wiser clinical decisions about the use of these technologies." Of current unwisdom there is ample evidence, fearlessly documented in the report. Elaborate and uncomfortable treatments of dubious advantage or none to the frail elderly are deployed on a scale unimaginable in Britain and for reasons that those familiar with United States medicine will understand.

The technologies are available, respected, and oversold. The same brave combination of technical virtuosity and indifference to cost that once took a handful of United States citizens to the moon serves in health care today to keep tens of thousands of them lingering, dependent and miserable here on earth, with equally questionable benefit. Powerful medicolegal considerations nudge doctors towards doing more rather than less. The peculiar funding mechanisms of American medicine also play their part. The overall costs now give rise to great concern, as do questions of access, institutional liability, individual choice, and human dignity.

The Office of Technology Assessment's admirable report faces up to all this in a detiiled survey that concentrates on five subjects: resuscitation, mechanical ventilation, dialysis for chronic renal failure, nutritional support, and life sustaining antibiotic treatment. The report recognises the extreme heterogeneity of the elderly, especially the elderly sick, and acknowledges the difficulties of predicting benefit from the various interventions. Current data on use and cost of the technologies are unreliable but none the less alarming, not least because "reimbursement is a major determinant of specific treatment options." Nutritional support is identified as the most controversial intervention, being easy to start, difficult to stop, continually expensive-that is, remunerative-and still the subject of fierce ethical debate. Renal dialysis poses special problems because of an anomaly 